ranked in the Academic Rankings of World Universities by Shanghai Jiao Tong University, and five ranked in the QS World-Class University Rankings. What do these rankings mean? The results of international university rankings vary according to selected indicators and weights. The U-Multirank does not provide comprehensive rankings, and some rankings now allow users to choose indicators and weights. It is becoming common for ranking providers to publish subject-based rankings and other rankings based on specific themes.

The golden age of university ranking providers has likely passed. Users, including universities and governments, now have more options for searching ranking results that fit their purposes. If it works for a better understanding of the rich context of universities, then it is good. However, further convergences or standardization of diversified university characteristics should be avoided through the efforts of various stakeholders.

\section{Revisiting the Academic Marketplace}

\section{Maria YudKeVICH}

Maria Yudkevich is vice rector at the National Research UniversityHigher School of Economics, Moscow, Russian Federation. E-mail: zүudkevich@gmail.com.

For many decades, our image of the university was associated with the metaphor of the ivory tower. While this metaphor is deeply embedded in our minds, we do not challenge it. However, it is neither ivory nor tower anymore. Indeed, university identity and borders become more and more unclear and illusory. There are several reasons for that.

First, new teaching and learning technologies challenge the university monopoly on both fundamental and applied knowledge. The number of students that follow courses on major online educational platforms grow exponentially, and faculty in many universities have to think about adjusting their courses in a way that they are still attractive to students. While advantages of a strong university in the provision of teaching services are evident, massive middle-tier institutions must identify how to compete for the attention of prospective students-not only with other universities but also with online providers. With lower transaction costs of combining curriculum from different providers in different universities, will the best and most demanding students still enroll in one university or will they combine experiences from different universities?
Second, traditionally junior faculty hired to tenure-track positions had a good chance of obtaining tenure. Today, chances are substantially lower. The share of permanent positions is getting significantly smaller in many countries and the age of obtaining a first stable position is increasing.

The monopoly of universities in producing basic research is also challenged by nonuniversity research organizations and corporations. These organizations compete for the best scholars and offer them competitive conditionsin some cases, including long-term employment-both in terms of salaries and opportunities for research.

Finally, there is an increasing pressure of productivity performance criteria and the need for constant search of external funding opportunities. This pressure may negatively affect academic norms of excellence, which assume the intrinsic motivation for the search of new knowledge and push universities toward considering faculty more as employees with clear performance indicators than as a community of scholars.

Massification of higher education leads to a substantial growth in a number of universities and also contributes to their diversity. Will universities from different parts of the quality continuum still recognize each other as species of one type in 20 years? Will there be much in common between top-tier research universities and those elsewhere in the academic hierarchy? Are we about to have traditional research universities becoming rare exceptions among numerous institutions of "used-to-be-university organizations"?

Since universities have been among the most stable organizations across the centuries, we might expect they will exist into the future. However, the questions are what will be their borders, how will their organizational identity be defined, and will the best and brightest minds be willing to come to work there.

\section{The Global Knowledge Soci- ety: Conflict Between Instru- mental and Principled Rea- son?}

\section{Pavel Zgaga}

Pavel Zgaga is professor at the Center for Educational Policy Studies at the University of Ljubljana and former minister of education, Slovenia. E-mail: pavel.zgaga@guest.arnes.si. 